\title{
Sucessão de cultivos e indicadores da qualidade do plantio direto no Planalto Médio do Rio Grande do Sul
}

\author{
Cropping sequences and no-till quality indicators in the Middle Plateau of Rio Grande do \\ Sul
}

\author{
Jardel Henrique Passinato ${ }^{1 \star}$, Mateus da Silva Brenner ${ }^{1}$, Ben-Hur Costa de Campos ${ }^{1}$, Karine Mariele \\ Kunz ${ }^{1}$, Carlos Gustavo Tornquist ${ }^{2}$, Sandra Meinen da Cruz ${ }^{1}$, Adriano Scholze Tramontini ${ }^{1}$ \\ ${ }^{1}$ Instituto Federal de Educação, Ciência e Tecnologia do Rio Grande do Sul, Ibirubá, RS, Brasil. *Autor para correspondência: \\ jardelhenriquepassinato@hotmail.com \\ ${ }^{2}$ Universidade Federal do Rio Grande do Sul, Porto Alegre, RS, Brasil.
}

Submissão: 28/12/2019 / Aceite: 22/06/2020

\begin{abstract}
RESUMO
O sistema plantio direto (SPD) reúne o maior complexo de tecnologias conservacionistas para solos tropicais e subtropicais, entretanto muitos produtores estão adotando parcialmente estes preceitos, potencializando a degradação do mesmo. O objetivo deste trabalho foi avaliar a qualidade do SPD em uma localidade, localizada no Planalto Médio do Rio Grande do Sul, observando qual a situação atual do manejo do solo e das glebas agrícolas da região conduzidas sob SPD. Foi realizado o monitoramento do uso do solo da localidade de Linha Cristal, situada no município de Selbach, RS, bem como a avaliação de glebas agrícolas que representassem diferentes manejos ali observados, além de uma mata nativa servindo de referência. Para isso, nestas glebas foram determinados os aportes de fitomassa seca (FMS) e o índice de cobertura (IC) da superfície do solo, a densidade (Ds), densidade crítica (Dsc) e grau de compactação (GC) do solo, além dos teores de matéria orgânica do solo (MOS). A análise estatística consistiu em análises univariadas (média e desvio padrão), já os resultados entre os teores de MOS e a Ds, também foram submetidos à análise de regressão. A área cultivada apresentou baixa diversidade de culturas no período de verão, predominando a soja (88,6\%). Maior parte do milho em 2016/2017, destinou-se a produção de silagem (59\%). Os cultivos de inverno foram mais diversificados, predominando a cultura do trigo, cevada, aveia branca e aveia preta. As médias anuais de FMS adicionada ao solo (13.147 e $11.508 \mathrm{~kg} / \mathrm{hectare} / \mathrm{ano}$ ) estiveram acima do mínimo para manter os níveis de MOS estipulado pela literatura $(9.000 \mathrm{~kg} /$ hectare/ano). As glebas agrícolas apresentaram a camada de 714 centímetros mais densa, onde apenas uma das glebas apresentou valor de Ds inferior a Dsc. Houve correlação linear inversa entre Ds e MOS, onde as áreas que continham maiores teores de MOS, apresentavam menores Ds.
\end{abstract}

PALAVRAS-CHAVE: semeadura direta, monocultura, manejo do solo, compactação do solo, matéria orgânica, fitomassa seca.

\begin{abstract}
The no-tillage system (SPD) brings together the largest complex of conservation technologies for tropical and subtropical soils, however many producers are partially adopting these precepts, enhancing its degradation. The objective of this work was to evaluate the quality of SPD in a locality, located in the Middle Plateau of Rio Grande do Sul, observing the current situation of soil management and agricultural plots in the region conducted under SPD. Land use monitoring was carried out at Linha Cristal, located in the city of Selbach, RS, as well as the evaluation of agricultural plots that represented the different managements observed there, as well as a native forest as reference. For this, the dry phytomass (DP) and the soil surface coverage rate $(\mathrm{CR})$, the density $(\mathrm{Sd})$, critical density $(\mathrm{Bd})$ and degree of compaction (DC) of the soil were determined, in addiction to soil organic matter (SOM). Statistical analysis consisted of univariate analyzes (mean and standard deviation), while the results between the SOM and Ds levels were also submitted to regression analysis. The cultivated area showed low crop diversity in summer crops, predominating soybean (88.6\%). Most of the corn in 2016/17 was destined to silage production (59\%). The winter harvests were more diversified, with predominance of wheat, barley, white oats and black oats. The annual average DP added to the soil (13,147 and $11,508 \mathrm{~kg} /$ hectare/year) were above the minimum to maintain the SOM levels stipulated by the literature $(9,000 \mathrm{~kg} / \mathrm{hectare} / \mathrm{year})$. Farmland presented the
\end{abstract}


densest 7-14 cm layer, where only one of the farmland presented Ds value lower than Dsc. There was an inverse linear correlation between Ds and MOS, where the areas containing the highest SOM contents had the lowest Ds.

KEYWORDS: zero-tillage, monoculture, soil management, soil compaction, organic matter, dry phytomass.

\section{INTRODUÇÃO}

O termo plantio direto (PD) ou semeadura direta, consiste na deposição de sementes, plantas ou partes de plantas no solo, sem a mobilização deste, exceto na linha ou cova de semeadura ou de plantio, junto à manutenção dos resíduos culturais na superfície do solo. Notou-se que para viabilizar a condução do PD de modo contínuo, este devia ser praticado como um sistema de manejo e não como uma simples prática de preparo reduzido. Dessa forma englobando além do PD, também a diversificação de espécies, através de rotação e/ou consórcio de culturas, cobertura permanente do solo, processo colher-semear e a adição de material orgânico suprindo a demanda biológica do solo, constituindo assim o sistema plantio direto (SPD) (FIORIN 2007, DENARDIN et al. 2012).

O sucesso deste sistema se dá, em grande parte, devido a fitomassa deixada pelas culturas de cobertura, somada aos resíduos vegetais deixados pelas culturas comerciais, exercerem o papel de proteção do solo. Sendo, dessa forma um dos principais parâmetros de referência para avaliar como o SPD está se desenvolvendo, através da quantificação e avaliação da uniformidade da distribuição da fitomassa (ALVARENGA et al. 2001).

Porém o abandono da mobilização mecânica do solo, condicionado pelo SPD, associado à modernização da agricultura, visando a otimização de suas práticas, tem levado ao aumento da intensidade do uso do solo. Necessitando muitas vezes de máquinas agrícolas de grande porte às quais, eventualmente, operam em condições de umidade inadequadas, condicionando à geração de camadas superficiais compactadas, podendo dessa forma, comprometer o desenvolvimento e a produtividade de plantas cultivadas (CHAMEN et al. 2003, DA SILVEIRA JUNIOR et al. 2012).

A densidade do solo (Ds), também chamada de densidade aparente ou global, consiste na relação entre a massa de solo seco e seu volume total, incluindo os espaços porosos, dessa forma refletindo no arranjo das partículas do solo, o qual define as características do espaço poroso (FERREIRA 2010).

O aumento da Ds ocasionado pelo homem (tráfego de máquinas) ou pelo pisoteio animal, resultando no rearranjamento das partículas do solo e consequente redução da sua porosidade é definida como compactação do solo; já o aumento da Ds por processos pedogenéticos (dessecação, iluviação ou precipitação química) é denominada como adensamento do solo (REICHERT et al. 2010). Portanto a Ds constitui-se como um indicador da estrutura do solo.

O aumento moderado na Ds não é prejudicial ao crescimento das culturas, pois dentro de certos limites, esse aumento pode contribuir para o armazenamento de água no solo e a capacidade de suporte de carga. Portanto a determinação do grau de compactação, bem como o conhecimento dos valores de densidade crítica do solo (Dsc), cujo a qual o crescimento radicular se torna restringido, auxiliam em tomadas de decisões referentes ao manejo do solo possibilitando melhorias em sua estrutura, visando melhores condições de desenvolvimento e produtividade das culturas (REICHERT et al. 2009).

A localidade de Linha Cristal (Selbach, RS) possui como principal atividade agrícola a produção de grãos, principalmente da cultura da soja, entretanto tal localidade tem apresentado uma falta de rotação de culturas. Dessa forma é necessário avaliar a qualidade do manejo realizado nessas áreas.

Portanto o objetivo deste trabalho foi avaliar a qualidade do SPD em uma região representativa dos sistemas agrícolas que predominam no Planalto Médio do Rio Grande do Sul, considerando sistemas de manejo do solo, incluindo avaliação da diversidade de cultivos utilizados, produção de fitomassa seca (FMS) e atributos físicos e químicos do solo.

\section{MATERIAL E MÉTODOS}

O estudo foi conduzido na localidade de Linha Cristal ( $\left.28^{\circ} 36^{\prime} 02^{\prime \prime} S, 52^{\circ} 56^{\prime} 53^{\prime \prime} \mathrm{O}\right)$, a qual corresponde a 2287 ha do território do município de Selbach, estando situado na região fisiográfica do Planalto Médio do estado do Rio Grande do Sul. A altitude média é 420 m, o clima da região é classificado como subtropical Cfa, conforme a classificação de Köppen (ÁLVAREZ et al. 2013). O solo predominante nesta região é do tipo Latossolo Vermelho Distroférrico (EMBRAPA 2013). A duração do estudo foi de duas safras agrícolas (abrangendo os cultivos de inverno e verão) compreendidas entre os anos de 2016 a 2018. 
Inicialmente os limites da área cultivada (lavouras) na região de estudo, foram identificados, explicitamente por fotointerpretação visual e delimitação manual de feições em imagens de alta resolução, disponíveis no programa Google Earth $\operatorname{Pro}^{\circledR}$. Em sequência, durante os diferentes períodos de cada safra (verão e inverno), no momento em que a maioria das culturas estavam no estádio fenológico correspondente à floração, foram conduzidas inspeções a campo, reconhecendo os cultivos implantados nas lavouras, bem como, possíveis alterações e/ou subdivisões das glebas. Posteriormente foram gerados mapas de cultivos, para cada safra, utilizando o programa QGIS $^{\circledR} 2.18 .24$.

Devido ao grande número de glebas agrícolas existentes na localidade, foram selecionadas, seis glebas agrícolas, que fossem representativas sobre os manejos adotados pelos produtores da região, para serem realizadas as amostragens relacionadas aos resíduos vegetais e solo. Dessa forma junto aos produtores, foram buscadas áreas que apresentassem diferentes históricos relacionados aos seus respectivos manejos, como áreas com manejo de solo em PD com e outras sem histórico de revolvimento do solo; com rotação ou somente sucessão de culturas; integração lavoura pecuária com diferentes lotações de animais e manejo de piquetes (Tabela 1). Além dessas áreas de cultivo, também foram coletadas amostras de solo de uma mata nativa, constituindo essas, como valor de referência de matéria orgânica do solo (MOS) e Ds.

Tabela 1. Área (ha) e histórico de mobilização do solo e cultivo das glebas avaliadas.

Table 1. Area (ha) and history of soil mobilization and cultivation of the evaluated plots.

\begin{tabular}{llll}
\hline Gleba & Área & Mobilização do solo & Histórico de cultivo \\
\hline G1 & 35,7 & Cada 4 anos, última em 2015 & Monocultura de soja \\
G2 & 25,6 & Sem desde 2003 & Rotação de culturas verão/inverno \\
G3 & 28,7 & Sem desde a década de 80 & Monocultura de soja \\
G4 & 28,3 & Sem desde a década de 80 & Monocultura de soja \\
G5 & 10,0 & Sem desde 2003 & ILP no inverno (2 animais/ha) \\
G6 & 15,0 & Última em 2016* & ILP no inverno** (3 animais/ha) \\
\hline
\end{tabular}

*Mobilização não ocorria com frequência; ${ }^{\star *}$ Com rotação de piquetes.

Nas glebas agrícolas ocorreram coletas de FMS, onde foram avaliadas a quantidade e a distribuição de resíduos vegetais (palhada) fornecidos pelas culturas sobre o solo. A quantificação consistiu em coletas de amostras referentes a $0,25 \mathrm{~m}^{2}$ de toda fitomassa existente na superfície do solo, com o auxílio de um quadro metálico com $0,5 \mathrm{~m}$ de lado, onde posteriormente, estas foram secas em estufa de circulação de ar forçado a $65{ }^{\circ} \mathrm{C}$ até adquirir peso constante. Já a estimativa do índice de cobertura (IC) do solo se deu através de uma adaptação do método proposto por LAFLEN et al. (1981), que consistiu em uma corda com 25 nós e espaçamento de 1 metro entre cada nó, a qual era esticada em diagonal com as linhas de cultivo, onde em cada nó foi identificada a presença ou ausência de resíduos.

As avaliações dos atributos físicos do solo consistiram na estimativa da Ds através da coleta de amostras de solo indeformadas com um extrator tipo Uhland com anéis de $7 \mathrm{~cm}$ de diâmetro e altura, nas profundidades de 0-7; 7-14 e 14-21 cm. Nessas amostras foram avaliados os teores de argila do solo $(\mathrm{g} / \mathrm{kg})$, servindo para a estimativa da densidade referência do solo (Ds ref) e da Dsc. A Ds ref foi obtida pela equação proposta por REICHERT et al. (2009), onde, Ds ref $=-0.00033$. argila +1.91655 . A Ds ref foi utilizada para a estimativa do grau de compactação do solo (GC). O GC consistiu na divisão da Ds pela Ds ref, multiplicada por 100, sendo expressa em percentual (\%). Já a Dsc foi obtida por valores estabelecidos na literatura agrupados por MICHELON (2005), considerando diferentes faixas de teores de argila do solo (Tabela 2).

Adicionalmente, os teores de MOS, indicadores da qualidade do manejo do solo, foram determinados nestas mesmas amostras, com o método de oxidação da MOS por solução sulfocrômica com calor externo e determinação espectrofotométrica do $\mathrm{Cr}^{+3}$ (TEDESCO et al. 1995).

As amostragens, tanto de FMS quanto de solo consistiram em três repetições por gleba. As coletas de FMS foram realizadas por volta de 15 dias após a colheita, já as amostragens de solo foram realizadas nas restevas de verão, antes da implantação de alguma cultura de inverno.

A análise estatística consistiu em análises univariadas para todos os atributos amostrados, sendo os dados de solo (teores de MOS e a Ds) submetidos à análise de regressão utilizando o programa Sisvar ${ }^{\circledR}$ 5.6. 
Tabela 2. Valores de densidade do solo estabelecidos como críticos (Dsc) para indicação de ocorrência de compactação dos solos em cada faixa de teor de argila dos solos.

Table 2. Soil density values established as critical (Bdc) to indicate soil compaction occurrence in each soil clay content range.

\begin{tabular}{lc}
\hline Faixa de argila $(\mathrm{g} / \mathrm{kg})$ & Dsc $\left(\mathrm{g} / \mathrm{cm}^{3}\right)$ \\
\hline $0-200$ & 1,60 \\
$200-300$ & 1,55 \\
$300-400$ & 1,50 \\
$400-500$ & 1,45 \\
$500-600$ & 1,40 \\
$600-700$ & 1,35 \\
$>700$ & 1,30 \\
\hline
\end{tabular}

Fonte: MICHELON (2005).

\section{RESULTADOS E DISCUSSÃO}

A área cultivada ocupava cerca de $79,7 \%$ do território da localidade, à qual apresentava por volta de 151 glebas de cultivo, já $11,7 \%$ da área constituía-se em áreas ocupadas por matas e os 8,5\% restantes da área se correspondiam nas sedes de propriedades e potreiros e/ou campos nativos (Tabela 3 ).

Tabela 3. Características do território da localidade de Linha Cristal, Selbach, RS.

Table 3. Territory characteristics of the locality of Linha Cristal, Selbach, RS.

\begin{tabular}{lcc}
\hline Característica do território & Área (ha) & Porcentagem (\%) \\
\hline Área cultivada & 1.823 & 79,7 \\
Área de matas & 268 & 11,7 \\
Área de propriedade e potreiros & 196 & 8,5 \\
\hline Área total & 2.287 & 100 \\
\hline
\end{tabular}

Durante o período de verão, tanto na safra de 2016/2017 quanto na safra de 2017/2018, a cultura predominante foi a soja (Tabela 4) ocupando, respectivamente, 1.590 e 1.663 ha, ou seja, 87,2 e 90,0\% da área cultivada, seguida da cultura do milho que ocupou 219 ha $(12,0 \%)$ na primeira safra avaliada e 135 ha $(7,4 \%)$ na segunda safra avaliada.

Conforme os dados apresentados pôde-se observar um aumento da área ocupada pela cultura da soja, quase $3 \%$ de uma safra para a outra. Em detrimento da cultura do milho, que apresentou uma redução de quase $5 \%$ em relação a área cultivada na safra anterior. Semelhante ao observado no acompanhamento da safras de grãos 2017/2018, realizado pela CONAB (2018), onde a área cultivada com soja no Brasil apresentou um aumento de 3,7\% e no estado do RS esse aumento foi de 2,2\% entre a safra 2016/2017 para a safra $2017 / 2018$ e já para a cultura do milho nesse mesmo período, houve uma redução de $5,4 \%$ no Brasil e $9,5 \%$ no RS.

No período de verão da safra 2016/2017, foi observado que nas áreas que receberam a cultura do milho, mais da metade foi destinada para silagem, correspondendo cerca de $59 \%$. Isso acaba reduzindo o aporte de fitomassa seca para o solo e consequentemente comprometendo a cobertura do mesmo. Além de que a maior parte dessas áreas acaba realizando a monocultura de milho, inclusive com dois cultivos no mesmo ano agrícola.

Já em relação as demais culturas utilizadas no período de verão observou-se 13,6 ha $(0,7 \%)$ cultivados com as culturas do sorgo e milheto na safra 2016/2017 e um aumento dessas para 38,5 ha $(2,1 \%)$ na safra de $2017 / 2018$ além da introdução de 2,9 ha $(0,5 \%)$ da cultura do Tifton.

Nos períodos de inverno houve uma maior diversidade de culturas implantadas, com uma ampla distribuição sobre o território da localidade (Figura 1). Onde no período de inverno de 2017 as culturas que apresentaram maiores proporções de área foram as culturas do trigo (32,1\%), cevada $(21,4 \%)$, aveia branca $(13,9 \%)$, aveia preta $(12,4 \%)$ e azevém $(11,8 \%)$, outras culturas corresponderam menos de $10 \%$ da área, que se constituíam no consórcio entre aveia e azevém, plantas espontâneas na área (pousio) e plantas perenes como o Tifton, sendo esses em sua maioria destinados a pastagem (Tabela 4).

No período de inverno subsequente (2018) a proporção de área cultivada com a cultura do trigo manteve-se praticamente estável $(32,0 \%)$ sendo novamente a cultura mais cultivada na área da localidade, seguida da aveia preta e aveia branca com 26,3 e 14,0\%, respectivamente. 
Tabela 4. Cenários de cultivos na área de estudo, localidade de Linha Cristal, Selbach, RS, durante as safras de 2016/2017 e 2017/2018 (períodos de verão 2016/2017 e 2017/2018; períodos de inverno 2017 e 2018).

Table 4. Crop scenarios in the study area, locality of Linha Cristal, Selbach, RS, during the 2016/2017 and 2017/2018 seasons (summer seasons 2016/2017 and 2017/2018; winter seasons 2017 and 2018).

\begin{tabular}{|c|c|c|c|c|c|}
\hline \multicolumn{3}{|c|}{ Verão 2016/2017 } & \multicolumn{3}{|c|}{ Verão 2017/2018 } \\
\hline Cultura & Glebas & AT (ha) & Cultura & Glebas & AT (ha) \\
\hline Soja & 123 & $1.590(87,2)^{*}$ & Soja & 137 & $1.633(90,0)$ \\
\hline Milho & 23 & $219(12,0)$ & Milho & 16 & $135(7,4)$ \\
\hline \multirow[t]{2}{*}{ Milheto/Sorgo } & 5 & $14(0,7)$ & Milheto/Sorgo & 6 & $38(2,1)$ \\
\hline & & & Tifton & 3 & $9(0,5)$ \\
\hline Total & 151 & $1.823(100)$ & Total & 162 & $1.816(100)$ \\
\hline \multicolumn{3}{|c|}{ Inverno 2017} & \multicolumn{3}{|c|}{ Inverno 2018} \\
\hline Cultura & Glebas & AT (ha) & Cultura & Glebas & AT (ha) \\
\hline Trigo & 44 & $568(32,1)$ & Trigo & 53 & $578(32,0)$ \\
\hline Cevada & 25 & $377(21,4)$ & Aveia Preta & 38 & $474(26,3)$ \\
\hline Aveia Branca & 28 & $246(13,9)$ & Aveia Branca & 35 & $252(14,0)$ \\
\hline Aveia Preta & 22 & $219(12,4)$ & Pousio & 25 & $184(10,2)$ \\
\hline Azevém & 22 & $208(11,8)$ & Azevém & 14 & $133(7,4)$ \\
\hline Pousio & 19 & $110(6,2)$ & Cevada & 9 & $93(5,1)$ \\
\hline Aveia+Azevém & 4 & $35(2,0)$ & Nabo & 6 & $78(4,3)$ \\
\hline \multirow[t]{2}{*}{ Tifton } & 2 & $4(0,2)$ & Aveia+Cevada & 2 & $7(0,4)$ \\
\hline & & & Tifton & 2 & $6(0,3)$ \\
\hline Total & 166 & $1.768(100)$ & Total & 184 & $1.804(100)$ \\
\hline
\end{tabular}

*Porcentagem correspondente à área total de cada cultura; AMG: Área média das glebas; AT: Área total.
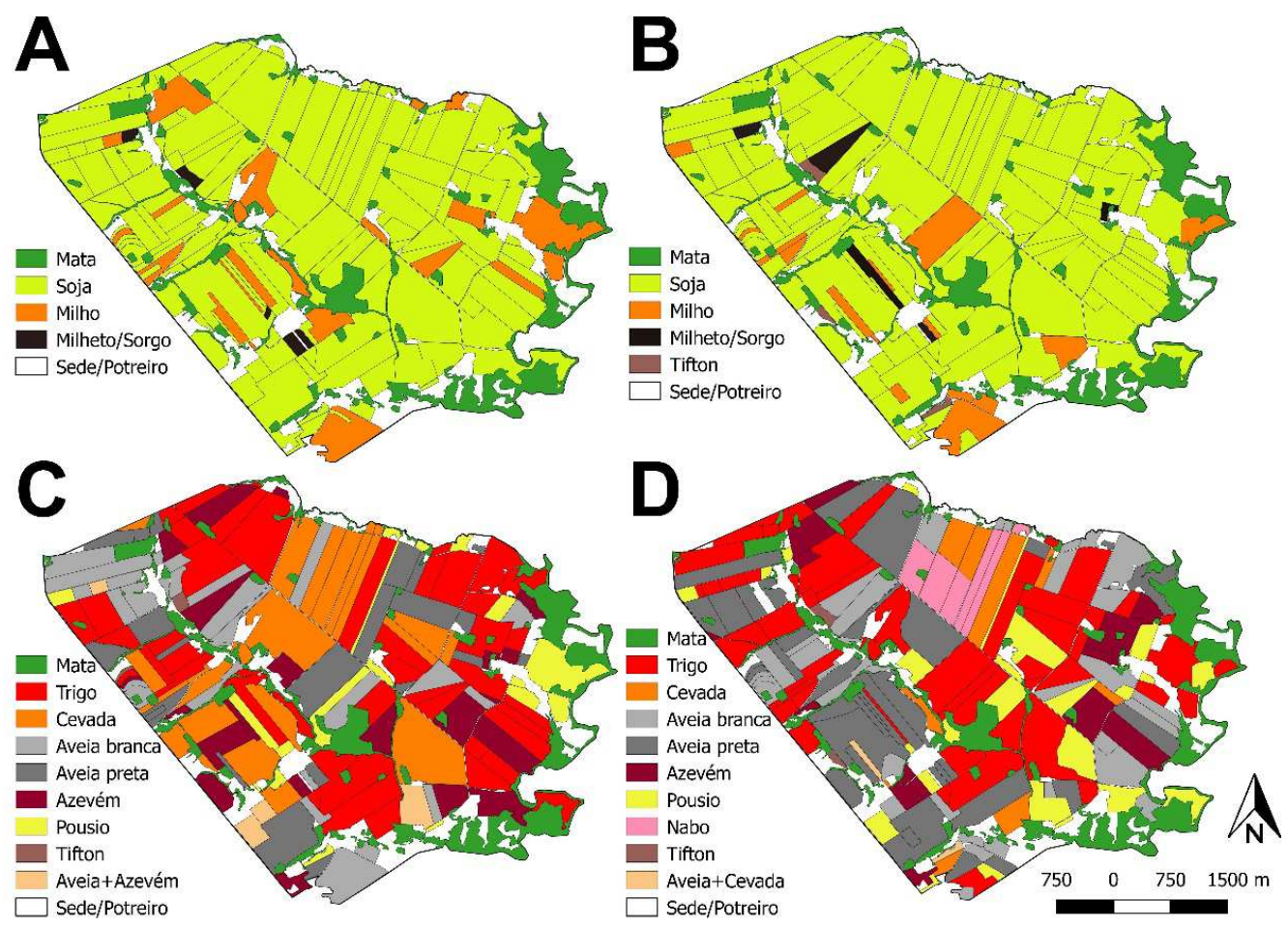

Figura 1. Uso do solo por culturas agrícolas na localidade de Linha Cristal, Selbach, RS, durante as safras de 2016/2017 e 2017/2018. A: Cultivos de verão 2016/2017; B: Cultivos de verão 2017/2018; C: Cultivos de inverno 2017; D: Cultivos de inverno 2018.

Figure 1. Land use by agricultural crops at Linha Cristal, Selbach, RS, during the 2016/2017 and 2017/2018 seasons. A: Summer season 2016/2017; B: Summer season 2017/2018; C: Winter season 2017; D: Winter season 2018. 
Além disso, observou-se um aumento da área em pousio para 10,2\%, a cultura do azevém apresentou $7,4 \%$ e já a cultura da cevada apresentou uma grande redução de área (16,3\% a menos), representando apenas $5,1 \%$ da área. Houve também a utilização da cultura do nabo forrageiro $(4,3 \%)$ e em menores proporções cultivos destinados a alimentação animal, sendo o consórcio de aveia com cevada e Tifton $(0,4$ e $0,3 \%)$.

Situação semelhante ao observado por BROETTO et al. (2016) no distrito de Santa Clara do Ingaí (Quinze de Novembro, RS) e bacias próximas ao distrito, onde no período compreendido entre os anos de 2012 a 2014 as principais culturas utilizadas foram o trigo e aveia durante o inverno e a soja no verão, ocupando por volta de $90 \%$ e $80 \%$ da área cultivada, respectivamente, em seus períodos de utilização, ocorrendo no distrito anteriormente mencionado, o monocultivo de soja em $55 \%$ das glebas durante esses três anos.

Em questão ao aporte de FMS sobre o solo (Tabela 5), as culturas de verão apresentaram maior quantidade média de FMS e IC, correspondendo a 7.892 e $6.533 \mathrm{~kg} / \mathrm{ha}$, com índices de 88 e $86 \%$ de cobertura, nas duas safras, respectivamente. Porém isso se deve à grande contribuição dos resíduos remanescentes dos cultivos de inverno nas restevas dos cultivos de verão.

Tabela 5. Quantidade de fitomassa seca (FMS) e índice de cobertura das glebas, durante as safras de 2016/2017 e 2017/2018 (períodos de verão 2016/2017 e 2017/2018; períodos de inverno 2017 e 2018).

Table 5. Amount of dry phytomass (DP) and land cover index, during the 2016/2017 and 2017/2018 seasons (summer seasons 2016/2017 and 2017/2018; winter seasons 2017 and 2018).

\begin{tabular}{|c|c|c|c|c|c|c|}
\hline \multirow{2}{*}{ Gleba } & \multicolumn{3}{|c|}{ Verão 2016/2017 } & \multicolumn{3}{|c|}{ Inverno 2017} \\
\hline & Cultura & FMS (kg/ha) & IC (\%) & Cultura & FMS (kg/ha) & IC (\%) \\
\hline G1 & Soja & 7.207 & 80 & Cevada & 6.455 & 69 \\
\hline G2 & Milho & 8.895 & 89 & Cevada & 9.633 & 69 \\
\hline G3 & Soja & 7.649 & 95 & Trigo & 4.694 & 93 \\
\hline G4 & Soja & 9.471 & 91 & Cevada & 4.137 & 89 \\
\hline G5 & Soja & 6.237 & 87 & Azevém** & 3.965 & 76 \\
\hline G6 & - & - & - & Aveia** & 2.649 & 51 \\
\hline Média & & 7.892 & 88 & & 5.255 & 75 \\
\hline \multirow{2}{*}{ Gleba } & \multicolumn{3}{|c|}{ Verão 2017/2018 } & \multicolumn{3}{|c|}{ Inverno 2018} \\
\hline & Cultura & FMS (kg/ha) & IC (\%) & Cultura & FMS (kg/ha) & IC (\%) \\
\hline $\mathrm{G} 1.1^{*}$ & Soja & 6.099 & 91 & Cevada & 4.678 & 80 \\
\hline G1.2 & - & - & - & Nabo & 4.282 & - \\
\hline G2 & Soja & 8.873 & 89 & Trigo & 6.815 & 85 \\
\hline G3 & Soja & 7.291 & 91 & Cevada & 4.827 & 95 \\
\hline G4.1* & Soja & 5.777 & 79 & Aveia Branca & 6.325 & 85 \\
\hline G4.2 & - & - & - & Nabo & 4.112 & - \\
\hline G5.1* & Soja & 4.311 & 88 & Pousio** & 2.347 & 77 \\
\hline G5.2 & - & - & - & Pousio & 3.153 & 87 \\
\hline G6. $1^{*}$ & Soja & 6.849 & 77 & Trigo & 5.277 & 85 \\
\hline G6.2 & - & - & - & Aveia Preta** & 3.163 & 80 \\
\hline Média & & 6.533 & 86 & & 4.498 & 84 \\
\hline
\end{tabular}

Nas restevas dos cultivos de inverno, a principal cultura antecessora utilizada no verão era a soja, que pertence à família Fabaceae, com baixa relação $\mathrm{C} / \mathrm{N}$ e portanto, com seus resíduos mais rapidamente decompostos. Essa situação contrasta com os resíduos das culturas predominantes no inverno, usualmente Poaceae, com relação C/N alta (LIMA FILHO et al. 2014). Portanto as culturas de inverno apresentaram menores valores médios de FMS sendo eles 5.255 e $4.498 \mathrm{~kg} / \mathrm{ha}$ com 75 e $84 \%$ de cobertura.

Além de que o clima pode ter influenciado no desenvolvimento de algumas dessas culturas de inverno, pois nesse período ocorreram temperaturas mais altas, sendo assim, de modo geral as culturas de inverno acabaram não se desenvolvendo como o esperado pelos produtores, pois ocorreu pouco afilhamento das plantas.

Segundo RODRIGUES (2000), a taxa máxima de afilhamento na cultura do trigo ocorre à temperatura 
de $25 \stackrel{\circ}{ } \mathrm{C}$, mas pode-se observar maior quantidade de afilhos a temperaturas mais baixas, já que a maior duração do período de afilhamento compensa o ritmo de crescimento mais lento. Assim, em temperaturas baixas, o ritmo de diferenciação de afilhos é mais lento; consequentemente, a duração do período de diferenciação é mais dilatada (maior produção fotossintética), produzindo maior número final de afilhos por planta.

Outro ponto importante que contribuiu para essa menor média de produção de FMS pelas culturas de inverno foi que algumas áreas são utilizadas para pastejo de animais durante esse período, reduzindo assim o aporte de FMS sobre o solo.

Quando observada a adição anual (em cada safra agrícola) de FMS ao solo, nos anos de 2017 e 2018 foram adicionados ao solo em média, respectivamente, 13.147 e $11.508 \mathrm{~kg} / \mathrm{ha} /$ ano de FMS, o que seria considerado excedente ao mínimo necessário para manter os teores de MOS. CAMPOS (2006), na região de Cruz Alta estudando a dinâmica do carbono sob sistemas de preparo de solo e de culturas em um Latossolo Vermelho, relata o elevado fluxo de $\mathrm{C}-\mathrm{CO}_{2}(9.000 \mathrm{~kg} / \mathrm{ha} / \mathrm{ano})$, o que exige a elevada adição de resíduos via fotossíntese para manter os níveis de MOS, portanto deve-se superar essa quantidade de FMS para então se manter ou até mesmo incrementar os níveis de $C$ no solo.

Em relação a Ds (Tabela 6), a mata nativa seguiu a tendência esperada de ser referência por ser um solo que não sofreu mobilização mecânica tendo sua estrutura preservada, apresentando os menores valores de Ds em seu perfil total amostrado $\left(1,03 \mathrm{~g} / \mathrm{cm}^{3}\right)$ e nas primeiras duas camadas estratificadas $(0-7 \mathrm{e}$ 7-14 cm) apresentando 0,84 e 1,02 g/cm 3 . Na última camada $(14-21 \mathrm{~cm})$, foram obtidos valores semelhantes a gleba G6 pelos quais não diferiram entre si dentro da margem de desvio padrão entre as repetições obtendo uma média de $1,23 \mathrm{~g} / \mathrm{cm}^{3}$, sendo que esses valores são menores do que a densidade crítica para esses solos, ou seja, não apresentando impedimentos para o desenvolvimento das plantas (Tabela 7).

Tabela 6. Teores de argila, densidade (Ds), densidade crítica (Dsc) e relação entre a densidade atual e a densidade crítica (Ds $\times$ Dsc) do solo em mata nativa e glebas da localidade de Linha Cristal, Selbach, RS conduzidas sob diferentes manejos de solo e histórico de culturas nas profundidades de $0-7 ; 7-14$ e $14-21 \mathrm{~cm}$.

Table 6. Clay contents, density (Sd), critical density (Bdc) and relationship between current density and critical density ( $S d \times$ Bdc) of native forest and farmlands of Linha Cristal, Selbach, RS conducted under different soil managements and crop history at depths of 0-7; 7-14 and 14-21 cm.

\begin{tabular}{|c|c|c|c|c|c|c|c|}
\hline \multirow{3}{*}{$\begin{array}{l}\text { Camada } \\
\text { (cm) }\end{array}$} & \multicolumn{7}{|c|}{ Gleba } \\
\hline & MT & G1 & G2 & G3 & G4 & G5 & G6 \\
\hline & \multicolumn{7}{|c|}{ Argila (\%) } \\
\hline $0-7$ & $31 \pm 3,1^{*}$ & $58 \pm 8,7$ & $72 \pm 11,1$ & $48 \pm 8,8$ & $57 \pm 5,7$ & $67 \pm 9,9$ & $54 \pm 9,3$ \\
\hline $7-14$ & $38 \pm 1,7$ & $61 \pm 15,3$ & $78 \pm 9,5$ & $67 \pm 4,9$ & $67 \pm 6,4$ & $81 \pm 1,3$ & $65 \pm 2,7$ \\
\hline $14-21$ & $44 \pm 7,4$ & $71 \pm 11,9$ & $83 \pm 6,5$ & $66 \pm 6,7$ & $79 \pm 6,2$ & $82 \pm 1,2$ & $77 \pm 9,1$ \\
\hline \multirow[t]{2}{*}{ Média } & 38 & 63 & 78 & 60 & 67 & 76 & 65 \\
\hline & \multicolumn{7}{|c|}{ Ds $\left(\mathrm{g} / \mathrm{cm}^{3}\right)$} \\
\hline $0-7$ & $0,84 \pm 0,05$ & $1,33 \pm 0,12$ & $1,25 \pm 0,12$ & $1,23 \pm 0,03$ & $1,46 \pm 0,05$ & $1,22 \pm 0,08$ & $1,22 \pm 0,10$ \\
\hline $7-14$ & $1,02 \pm 0,06$ & $1,48 \pm 0,03$ & $1,53 \pm 0,03$ & $1,35 \pm 0,07$ & $1,56 \pm 0,11$ & $1,37 \pm 0,05$ & $1,29 \pm 0,04$ \\
\hline $14-21$ & $1,23 \pm 0,03$ & $1,46 \pm 0,11$ & $1,47 \pm 0,11$ & $1,33 \pm 0,05$ & $1,46 \pm 0,09$ & $1,29 \pm 0,08$ & $1,21 \pm 0,02$ \\
\hline \multirow[t]{2}{*}{ Média } & 1,03 & 1,42 & 1,42 & 1,30 & 1,49 & 1,30 & 1,24 \\
\hline & \multicolumn{7}{|c|}{$\operatorname{Dsc}\left(\mathrm{g} / \mathrm{cm}^{3}\right)^{\star \star}$} \\
\hline $0-7$ & 1,50 & 1,40 & 1,30 & 1,45 & 1,40 & 1,35 & 1,40 \\
\hline $7-14$ & 1,50 & 1,35 & 1,30 & 1,35 & 1,35 & 1,30 & 1,35 \\
\hline $14-21$ & 1,45 & 1,30 & 1,30 & 1,35 & 1,30 & 1,30 & 1,30 \\
\hline \multirow[t]{2}{*}{ Média } & 1,50 & 1,35 & 1,30 & 1,40 & 1,35 & 1,30 & 1,35 \\
\hline & \multicolumn{7}{|c|}{ Ds ref $\left(\mathrm{g} / \mathrm{cm}^{3}\right)^{\star \star \star}$} \\
\hline $0-7$ & 1,81 & 1,73 & 1,68 & 1,76 & 1,73 & 1,70 & 1,74 \\
\hline $7-14$ & 1,79 & 1,72 & 1,66 & 1,70 & 1,70 & 1,65 & 1,70 \\
\hline $14-21$ & 1,77 & 1,68 & 1,64 & 1,70 & 1,66 & 1,65 & 1,66 \\
\hline Média & 1,79 & 1,71 & 1,66 & 1,72 & 1,70 & 1,67 & 1,70 \\
\hline
\end{tabular}

${ }^{*}$ Desvio padrão das amostras. ${ }^{* *}$ Valores estimados através de dados de MICHELON (2005). ${ }^{* *}$ Valores calculados através de equação proposta por REICHERT et al. (2009). MT = Mata nativa; G1 = Escarificado em 2015; G2 = Rotação de culturas; G3 = Monocultura soja; G4 = Monocultura soja; G5 = Integração lavoura pecuária (ILP) menor lotação; G6 = ILP maior lotação pastejo rotacionado e escarificado em 2016. 
Tabela 7. Relação entre a densidade atual e a densidade crítica (Ds x Dsc) e grau de compactação do solo (GC) em mata nativa e glebas da localidade de Linha Cristal, Selbach, RS conduzidas sob diferentes manejos de solo e histórico de culturas nas profundidades de 0-7; 7-14 e 14-21 cm.

Table 7. Relationship between current density and critical density ( $S d \times B d c)$ and degree of soil compaction $(D C)$ in native forest and farmlands of Linha Cristal, Selbach, RS conducted under different soil management and crop history at depths of 0-7; 7-14 and 14-21 cm.

\begin{tabular}{lcccccccc}
\hline \multirow{2}{*}{ Gleba } & \multicolumn{3}{c}{ Ds / Dsc (\%) } & \multicolumn{3}{c}{ GC (\%) } \\
\cline { 2 - 9 } & $0-7$ & $7-14$ & $14-21$ & Média & $0-7$ & $7-14$ & $14-21$ & Média \\
\hline MT & 56 & 68 & 85 & 69 & 46 & 57 & 69 & 58 \\
G1 & 95 & 110 & 112 & 105 & 77 & 86 & 87 & 83 \\
G2 & 96 & 118 & 113 & 109 & 74 & 92 & 89 & 86 \\
G3 & 85 & 100 & 99 & 93 & 70 & 80 & 78 & 76 \\
G4 & 104 & 116 & 112 & 110 & 84 & 92 & 88 & 88 \\
G5 & 90 & 105 & 99 & 100 & 72 & 83 & 78 & 78 \\
G6 & 87 & 96 & 93 & 92 & 70 & 76 & 73 & 73 \\
\hline
\end{tabular}

* Ds / Dsc = valores < 100 estão abaixo da Dsc; Valores > 100 estão acima da Dsc. MT = Mata nativa; G1 = Escarificado em 2015; G2 = Rotação de culturas; G3 = Monocultura soja; G4 = Monocultura soja; G5 = Integração lavoura pecuária (ILP) menor lotação; G6 = ILP maior lotação pastejo rotacionado e escarificado em 2016.

Já as glebas agrícolas em geral seguiram a tendência de apresentar a camada intermediária estratificada $(7-14 \mathrm{~cm})$ mais densa e com os maiores GC, sendo na maioria dos casos densidades superiores a Dsc pela faixa de teor de argila do solo, onde apenas uma das seis glebas amostradas apresentou valor de Ds abaixo da Dsc, levando-se em consideração a margem de desvio padrão, a qual foi a gleba G6 que possuía como Dsc para faixa de argila nesta camada de $1,35 \mathrm{~g} / \mathrm{cm}^{3}$ e a Ds verificada foi de $1,29 \mathrm{~g} / \mathrm{cm}^{3}$. Semelhante ao observado por SECCO et al. (2009), onde as maiores Ds e Rp, em Latossolos cultivados sob sistema plantio direto, ocorrem na camada de 7-12 cm.

Considerando todas as camadas amostradas, com exceção da gleba G6, todas as outras glebas apresentaram ao menos uma camada com valores de Ds igual ou superior a Dsc para sua faixa de argila. Vale ressaltar que a gleba G6 havia passado por um manejo de mobilização do solo, no caso uma escarificação para a incorporação de calcário aproximadamente 6 meses antes das coletas de solo, porém esse efeito é limitado.

SECCO \& REINERT (1997) constataram que o efeito residual da escarificação em um Latossolo de textura muito argilosa no RS, não supera 10 meses, já DRESCHER et al. (2016) também nesse estado e em um Latossolo Vermelho, observaram que esse efeito se manteve apenas por 6 meses.

Através das análises realizadas, também constatou-se que a gleba G4 apresentou compactação em todas camadas de seu perfil por apresentar valores maiores ao de Dsc. Um fator que pode ter contribuído para esse cenário foi os menores valores dos teores de MOS (Tabela 8) em seu perfil em relação as demais glebas, principalmente nas duas primeiras camadas, o que tornou esse solo mais suscetível a compactação, pois a MOS junto aos óxidos e hidróxidos atuam como agentes cimentantes entre as partículas primárias e secundárias do solo, proporcionando uma maior estabilidade dos agregados (KLEIN 2008).

Isso fica mais evidente quando se compara com a gleba G3, que possuía um histórico de manejo e condução semelhante ao da gleba G4, mas apresenta maiores teores de MOS e menores valores de Ds, sendo que nenhuma camada apresenta valores que ultrapassassem a Dsc.

Os valores de Dsc estabelecidos por MICHELON (2005), correspondem a um GC médio de $82 \%$, variando entre 77 a $86 \%$ entre as faixas de argila, estimado pela equação proposta por REICHERT et al. (2009), valores os quais estão de acordo com SUZUKI et al. (2007), cujo o qual, afirma que os valores ótimos de GC para a maioria das culturas, situa-se entre 77 e $87 \%$.

Assim como na Ds, em relação a MOS (Tabela 8) a mata nativa de referência obteve os melhores resultados apresentando os maiores teores de MOS tanto na média do perfil total como em cada uma das camadas estratificadas.

Todas as áreas amostradas, independente do seu histórico apresentaram a tendência de conter os maiores teores de MOS nas camadas iniciais diminuindo seus teores gradualmente ao longo do aumento da profundidade, o que é característica desse tipo de solo (Latossolo).

Considerando o perfil total avaliado $(0-20 \mathrm{~cm})$, apenas a mata nativa apresentou valores considerados 
alto de MOS. Nas glebas agrícolas somente as glebas G3 e G6 apresentaram teores médios de MOS, já o restante das glebas apresentaram níveis baixos de MOS conforme o Manual de Calagem e Adubação para os Estados de SC e RS (SOCIEDADE BRASILEIRA DE CIÊNCIA DO SOLO 2016).

Tabela 8. Teores (\%) de matéria orgânica do solo (MOS) em mata nativa e glebas agrícolas da localidade de Linha Cristal, Selbach, RS conduzidas sob diferentes manejos de solo e histórico de culturas nas profundidades de 0-7; 7-14 e 14-21 cm.

Table 8. Contents (\%) of soil organic matter (SOM) in native forest and farmlands of Linha Cristal, Selbach, $R S$ conducted under different soil management and crop history at depths of 0-7; 7-14 and 14-21 $\mathrm{cm}$.

\begin{tabular}{lllll}
\hline \multirow{2}{*}{ Gleba } & \multicolumn{4}{c}{ Profundidade $(\mathrm{cm})$} \\
\cline { 2 - 5 } & \multicolumn{1}{c}{$0-7$} & $7-14$ & $14-21$ & Média \\
\hline MT & $7,0 \pm 0,8^{*}$ & $3,9 \pm 1,3$ & $2,3 \pm 0,8$ & 4,4 \\
G1 & $3,0 \pm 0,3$ & $2,4 \pm 0,2$ & $1,8 \pm 0,3$ & 2,4 \\
G2 & $3,0 \pm 0,4$ & $2,0 \pm 0,2$ & $1,7 \pm 0,2$ & 2,3 \\
G3 & $3,8 \pm 0,5$ & $2,7 \pm 0,5$ & $2,4 \pm 0,4$ & 3,0 \\
G4 & $2,8 \pm 0,7$ & $2,0 \pm 0,2$ & $1,7 \pm 0,3$ & 2,2 \\
G5 & $3,1 \pm 0,9$ & $1,9 \pm 0,2$ & $1,8 \pm 0,1$ & 2,3 \\
G6 & $4,1 \pm 1,6$ & $2,4 \pm 0,3$ & $1,4 \pm 0,4$ & 2,7 \\
\hline Média & 3,8 & 2,5 & 1,9 & \\
\hline
\end{tabular}

${ }^{*}$ Desvio padrão das amostras. MT = Mata nativa; G1 = Escarificado em 2015; G2 = Rotação de culturas; G3 = Monocultura soja; G4 = Monocultura soja; G5 = Integração lavoura pecuária (ILP) menor lotação; G6 = ILP maior lotação pastejo rotacionado e escarificado em 2016.

Através da análise de regressão entre os teores de MOS e a Ds (Figura 2), verifica-se que há uma correlação linear negativa, onde a medida que se aumentaram os teores de $\mathrm{MO}$, menores foram os valores de Ds encontrados, apresentando um coeficiente de determinação $\left(R^{2}\right)$ de 0,53 para as médias do perfil total amostrado $(0-21 \mathrm{~cm})$.
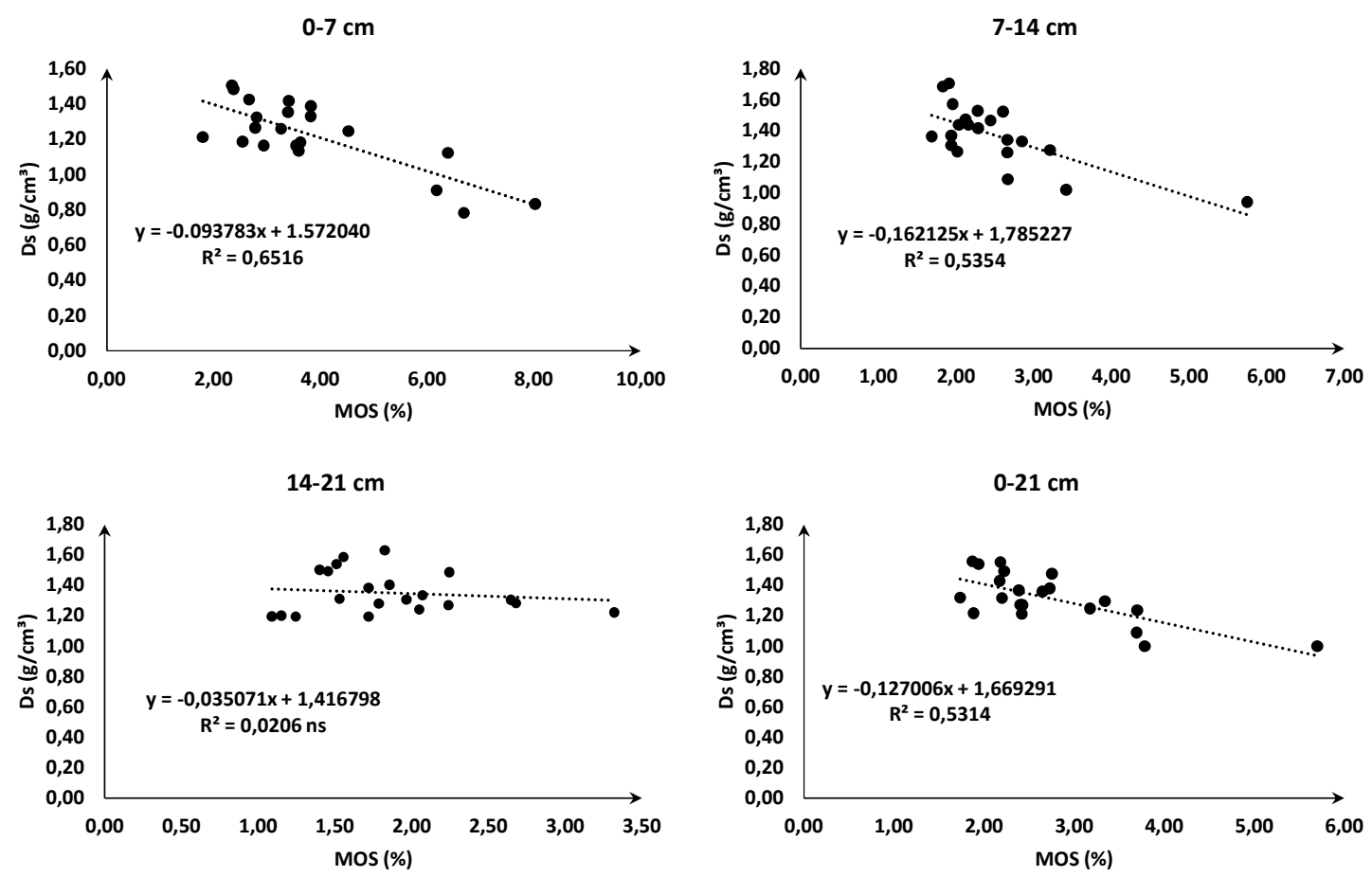

Figura 2. Análise de regressão entre teores de matéria orgânica do solo (MOS) e a densidade do solo (Ds) de glebas e mata nativa nas profundidades de $0-7 ; 7-14 ; 14-21$ e $0-21 \mathrm{~cm}$, na localidade de Linha Cristal, Selbach, RS. *ns: não significativo ( $p>0,05)$.

Figure 2. Regression analysis between soil organic matter (SOM) content and soil density (Sd) of farmlands and native forest at depths of 0-7; 7-14; $14-21$ and 0-21 cm, at Linha Cristal, Selbach, RS. *ns: not significant $(p>0.05)$. 
Devido à essas coletas serem realizadas em glebas com históricos totalmente distintos e essas representarem uma grande extensão de área, o $\mathrm{R}^{2}$ não foi muito elevado, mas considerando a linha de tendência, o presente trabalho corrobora com SANTOS (2016), que em um estudo relacionado ao suporte de carga em solos (Latossolos e Argissolos) de várias regiões do RS, através de uma correlação simples de Pearson, obteve uma correlação negativa com um $\mathrm{R}$ de 0,82 (Ds e CO) em áreas com vegetações nativas nas camadas de 10 a $15 \mathrm{~cm}$.

FRANZLUEBBERS \& STUEDEMANN (2010) em um experimento que avaliou as mudanças na superfície do solo submetido a diferentes manejos de pastagem (zonas e pressões de pastejo, fontes de adubação e camadas do solo) durante 12 anos na região sudoeste dos Estados Unidos, também observaram uma relação inversa forte entre a Ds e CO em um perfil de amostragem total de $0-20 \mathrm{~cm}$, obtendo um $\mathrm{R}^{2}$ de 0,91 .

Quando se observou as camadas isoladamente, as duas primeiras $\left(0-7\right.$ e 7-14 cm) apresentam o $\mathrm{R}^{2}$ de 0,65 e 0,54, respectivamente, indicando também essa correlação, mas já na profundidade de $14-21 \mathrm{~cm}$, o resultado da regressão não foi significativo, resultando num $\mathrm{R}^{2}$ próximo a zero, indicando que ao longo do aumento da profundidade diminuiu-se a correlação, não havendo mais esta a partir dos $14 \mathrm{~cm}$.

Essa dinâmica pode ser explicada pelos baixos teores de MOS nessa camada mais profunda os quais foram semelhantes desde solos sem a intervenção mecânica quanto em solos que haviam sido submetidos a essas operações. Além de que as duas primeiras camadas são as que estão mais sujeitas as transformações devido a maioria das operações nas glebas agrícolas ocorrerem nas mesmas e dificilmente ocorrerem nas camadas mais profundas.

\section{CONCLUSÃO}

Os valores médios anuais de FMS adicionada à superfície solo, foram superiores aos valores mínimos para a manutenção dos níveis de MOS, em relação aos valores estipulados pela literatura.

Os teores de MOS e Ds apresentaram correlação linear significativa, tanto para o perfil total avaliado $(0-21 \mathrm{~cm})$ quanto para as duas primeiras camadas $(0-7$ e 7-14 cm), onde a medida que se aumentaram os teores de MOS, menores foram os valores de Ds. Entretanto na profundidade de $14-21 \mathrm{~cm}$ não ocorreu essa correlação, indicando que ao longo do aumento da profundidade diminuiu-se a correlação, não havendo mais, a partir dos $14 \mathrm{~cm}$.

As áreas da localidade apresentaram baixa diversidade de culturas, principalmente no período de verão, havendo o predomínio da cultura da soja. E ainda a maior parte do milho cultivado na localidade (2016/2017) foi destinado a produção de silagem (59\%). Já no período de inverno, as glebas apresentaram maior diversidade de culturas, predominando culturas produtoras de grãos como trigo, cevada, aveia branca e forrageiras como aveia preta.

As glebas agrícolas seguiram a tendência de apresentar a camada de 7-14 cm mais densa, sendo, em sua maioria, densidades superiores a Dsc, onde apenas uma das seis glebas amostradas apresentou valor de Ds inferior a Dsc nesta camada.

\section{AGRADECIMENTOS}

Ao Instituto Federal de Educação, Ciência e Tecnologia do Rio Grande do Sul (IFRS) - Campus Ibirubá, pela estrutura e concessão de bolsa de Iniciação Científica e/ou Tecnológica no Ensino Superior (BICTES) e aos produtores da área referente a este estudo, por permitirem as coletas em suas propriedades.

\section{REFERÊNCIAS}

ALVARENGA RC et al. 2001. Plantas de cobertura de solo para sistema plantio direto. Informe Agropecuário 22: 25-36. ÁLVAREZ CA et al. 2013. Köppen's climate classification map for Brazil. Meteorologische Zeitschrift 22: 711-728.

BROETTO T. 2016. Indicadores de impactos ambientais da agropecuária em bacias hidrográficas. Tese (Doutorado em Ciência do Solo). Porto Alegre: UFRGS. 200p.

CAMPOS BC. 2006. Dinâmica do carbono em Latossolo vermelho sob sistemas de preparo de solo e de culturas. Tese (Doutorado em Agronomia). Santa Maria: UFSM. 188p.

CHAMEN T et al. 2003. Prevention strategies for field traffic-induced subsoil compaction: A review. Equipment and field practices. Soil and Tillage Research 73: 161-174.

CONAB. 2018. Companhia Nacional de Abastecimento. Acompanhamento da safra brasileira de grãos. Safra 2017/18. Brasília: CONAB. 148p

DA SILVEIRA JUNIOR SD et al. 2012. Qualidade física de um latossolo vermelho sob plantio direto submetido à descompactação mecânica e biológica. Revista Brasileira de Ciência do Solo 36: 1854-1867. 
DENARDIN JE et al. 2012. Diretrizes do sistema plantio direto no contexto da agricultura conservacionista. Passo Fundo: Embrapa Trigo. 15p. (Documentos online 141).

DRESCHER MS et al. 2016. Duração das alterações em propriedades físico hídricas de Latossolo argiloso decorrentes da escarificação mecânica. Pesquisa Agropecuária Brasileira 51: 159-168.

EMBRAPA. 2013. Empresa Brasileira de Pesquisa Agropecuária. Sistema Brasileiro de Classificação dos Solos. 3.ed. Brasília: EMBRAPA. 353p.

FERREIRA MM. 2010. Caracterização física do solo. In: VAN LIER QJ (Ed.). Física do solo. Viçosa: Sociedade Brasileira de Ciência do Solo. p.1-28.

FIORIN JE. 2007. Manejo e fertilidade do solo no Sistema Plantio Direto. Passo Fundo. Berthier. 184p.

FRANZLUEBBERS AJ \& STUEDEMANN JA. 2010. Surface Soil Changes during Twelve Years of Pasture Management in the Southern Piedmont USA. Soil Science Society of America 74: 2131-2141.

LAFLEN JM et al. 1981. Measuring crop residue cover. Journal of Soil and Water Conservation 36: 341-343.

LIMA FILHO OF et al. 2014. Adubação verde e plantas de cobertura no Brasil: fundamentos e prática. Brasília: Embrapa. 507p.

KLEIN VA. 2008. Física do solo. Passo Fundo: UPF. 212p.

MICHELON CJ. 2005. Qualidade física de solos irrigados do Rio Grande do Sul e do Brasil Central. Dissertação (Mestrado em Ciência do Solo). Santa Maria: UFSM. 115p.

REICHERT JM et al. 2010. Mecânica do solo. In: VAN LIER QJ (Ed.). Física do solo. Capítulo 1. Viçosa: Sociedade Brasileira de Ciência do Solo. p.29-102.

REICHERT JM et al. 2009. Reference bulk density and critical degree-of-compactness for no-till crop production in subtropical highly weathered soils. Soil and Tillage Research 102: 242-254.

RODRIGUES O. 2000. Manejo de trigo: bases ecofisiológicas. In: CUNHA GR \& BACALTCHUK B (Ed.). Tecnologia para produzir trigo no Rio Grande do Sul. Série Culturas - Trigo. Porto Alegre: Assembléia Legislativa do Rio Grande do Sul. p.120-169.

SANTOS TF. 2016. Relação entre atributos físicos, químicos, mineralógicos e capacidade de suporte de carga de solos do Rio Grande do Sul. Dissertação (Mestrado em Ciência do Solo). Porto Alegre: UFRGS. 66p.

SECCO D et al. 2009. Atributos físicos e rendimento de grãos de trigo, soja e milho em dois Latossolos compactados e escarificados. Ciência Rural 39: 58-64.

SECCO D \& REINERT DJ. 1997. Efeitos imediato e residual de escarificadores em Latossolo Vermelho-escuro sob plantio direto. Engenharia Agrícola 16: 52-61.

SOCIEDADE BRASILEIRA DE CIÊNCIA DO SOLO. 2016. Manual de calagem e adubação para os Estados do Rio Grande do Sul e de Santa Catarina. Núcleo regional Sul. Comissão de Química e Fertilidade do Solo - RS/SC. Frederico Westphalen: SBCS.376p.

SUZUKI LEAS et al. 2007. Grau de compactação, propriedades físicas e rendimento de culturas em Latossolo e Argissolo. Pesquisa Agropecuária Brasileira 42: 1159-1167.

TEDESCO MJ et al. 1995. Análises de solo, plantas e outros materiais. Porto Alegre: UFRGS 174p. (Boletim técnico 5). 